\title{
Avaliação da usinabilidade do aço inoxidảvel supermartensítico na operação de torneamento
}

\author{
Evaluation of the machinability of \\ supermartensitic stainless steel \\ when turning
}

Deibe Valgas dos Santos ${ }^{1,2}$, Alexandre Mendes Abrão ${ }^{2}$,
Anderson Júnior dos Santos

\footnotetext{
${ }^{1}$ Centro Universitário UNA, Av. Afonso Vaz de Melo, 640, CEP: 30640-970, Barreiro, Belo Horizonte, MG, Brasil.

${ }^{2}$ Programa de Pós-Graduação em Engenharia de Produção, Escola de Engenharia, Universidade Federal de Minas Gerais, Av. Antônio Carlos, 6627, CEP: 31270-901, Belo Horizonte, MG, Brasil.

e-mail: deibe.santos@prof.una.br, abrao@demec.ufmg.br, ndersonsantos@hotmail.com
}

\begin{abstract}
RESUMO
A exploração de petróleo e gás na camada denominada Pré-sal tem apresentado grandes desafios para a cadeia de fornecedores de alguns itens inoxidáveis, particularmente no que se refere às operações de usinagem destes componentes. A seleção de ligas com elevada resistência à corrosão, tenacidade e propriedades mecânicas é um processo complexo, uma vez que as condições sob as quais estes materiais estão expostos nos campos de exploração são cada vez mais severas, principalmente em águas profundas. Apesar de todo o investimento no setor, ainda existe a necessidade de estudos sobre o processo de usinagem destas ligas. O objetivo principal deste trabalho é o estudo do torneamento do aço inoxidável supermartensítico da classe CA6NM com ferramentas de metal duro correspondentes às classes ISO M10 e ISO M10-20 revestidas com $\mathrm{TiCN}+\mathrm{Al}_{2} \mathrm{O}_{3}+\mathrm{TiN}$ e à classe ISO M30-40 revestida por $(\mathrm{Ti}, \mathrm{Al}) \mathrm{N}$ com alto teor de Al. Além do material da ferramenta, foi avaliada a influência da velocidade de corte e da pressão de aplicação do fluido de corte (baixa pressão de 0,1 bar e alta pressão de 80 bar) sobre a rugosidade da superfície usinada (desvio médio aritmético Ra), vida da ferramenta de corte e mecanismos de desgaste predominantes. Os resultados indicaram que o material da ferramenta, velocidade de corte e pressão de aplicação do fluido de corte não apresentaram influência estatística sobre a rugosidade. Quanto ao desgaste de flanco e vida dos insertos, estes foram afetados por todos parâmetros investigados e o inserto da classe ISO M10 revestido com TiCN $+\mathrm{Al}_{2} \mathrm{O}_{3}+\mathrm{TiN}$ foi o que apresentou melhor desempenho.
\end{abstract}

Palavras-chave: aço inoxidável supermartensítico, torneamento, metal duro revestido.

\section{ABSTRACT}

The supply chain for oil and gas extraction currently faces great challenges with regard to the machinability of stainless steels for such applications. The selection of alloys with high corrosion resistance, toughness and mechanical properties is a complex process, since the conditions under which these materials are exposed are increasingly severe, especially under deep waters. Despite the investment in the sector, the need for studies on the machinability of these alloys remains. The principal goal of this work is the study the behavior of CA6NM supermartensitic stainless steel when turning with coated carbide tools corresponding to ISO grades M10 and M10-20 coated with TiCN $+\mathrm{Al}_{2} \mathrm{O}_{3}+\mathrm{TiN}$ and to grade ISO M30-40 coated with (Ti, Al) N possessing high $\mathrm{Al}$ content. Additionally, the influence of cutting fluid pressure ( 0.1 and 80 bar, respectively) and cutting speed on machined surface roughness (Ra parameter), tool life and wear mechanisms was assessed. The findings indicated that tool material, cutting fluid pressure and cutting speed did not present statistical influence on roughness. In contrast, all the investigated factors affected tool life and wear and the ISO grade $\mathrm{M} 10$ insert coated with $\mathrm{TiCN}+\mathrm{Al}_{2} \mathrm{O}_{3}+\mathrm{TiN}$ presented best overall performance.

Keywords: supermartensitic stainless steel, turning, coated carbide tools. 


\section{INTRODUÇÃO}

A exploração e produção de petróleo proveniente do Pré-sal já é uma realidade consolidada. Grandes recursos são investidos em desenvolvimentos tecnológicos a fim de fomentar o conhecimento e a formação de uma cadeia de bens e serviços que possam suprir as necessidades oriundas do setor de exploração e produção de petróleo. Estima-se que em 2021 a produção mundial de óleo e gás alcance 3,41 milhões de barris de óleo equivalente (óleo e gás) por dia. A Petrobrás e parceiros atualmente produzem cerca de 1,5 milhão de barris de óleo equivalente por dia no Pré-sal da Bacia de Santos (campo Lula). A descoberta de campos de petróleo no Pré-sal impulsionou ainda mais os investimentos em pesquisa no setor devido à complexidade na exploração e extração do petróleo [1].

A descoberta de novos campos de petróleo a uma profundidade de aproximadamente de 2000 metros apresenta vários desafios à sua extração em comparação aos poços tradicionais, dentre eles concentrações mais elevadas de $\mathrm{CO}_{2}$ e de $\mathrm{H}_{2} \mathrm{~S}$ (que aceleram o processo de corrosão). Nestas situações, torna-se viável apenas a utilização dos aços inoxidáveis supermartensíticos (AISM) e super duplex (AISD), pois estes possuem características e propriedades mecânicas adequadas para atender aos desafios tecnológicos propostos pelo novo cenário de exploração e produção[2]. Desta forma, fabricantes de alguns itens inoxidáveis enfrentem grandes desafios na usinagem destes componentes.

Morelo [3] e Machado et al. [4] apontam que a integridade superficial de um material está relacionada à topologia e às propriedades físicas, químicas, mecânicas e metalúrgicas da superfície. Certamente, a integridade superficial de um componente é um fator importante a ser considerado no processo de usinagem devido à condição da superfície influenciar o desempenho do componente, por exemplo, com respeito à resistência à fadiga e à corrosão. A integridade superficial no âmbito do acabamento da superfície (rugosidade) desempenha um papel importante no comportamento dos componentes mecânicos, podendo influenciar a qualidade de deslizamento, a resistência ao desgaste, a possibilidade de ajuste forçado, a resistência oferecida pela superfície ao escoamento de fluidos e lubrificantes, a qualidade de aderência que a estrutura oferece às camadas protetoras, resistência à corrosão e à fadiga, na vedação e, finalmente, na aparência [5].

Oliveira [6] avaliou a rugosidade após o torneamento do aço inoxidável supermatensítico (Super Cromo 13\%) com insertos de metal duro utlizando condições distintas de lubri-refrigeração (alta pressão, baixa pressão, corte a seco e com ar comprimido) e duas direções de aplicação da lubri-refrigeração (na superficie de saída e na superficie de folga). Os resultados mostraram que a rugosidade após o corte a seco mostrou-se inaceitável, produzindo os piores acabamentos. A aplicação de fluido de corte sob alta pressão na superfície de saída gerou melhor qualidade superficial comparada ao corte a seco e com aplicação de ar comprimido. Identificou-se que a combinação da aplicação de ar comprimido na superfície de folga simultaneamente ao fluido de corte sob alta pressão na direção da superfície de saída propiciou o melhor resultado.

A integridade da superfície da peça envolve uma série de fatores importantes para o seu controle. Um acabamento superficial desejado envolve o controle da vida da ferramenta de corte, expressa pelo tempo em que esta consegue realizar o corte de forma efetiva sem que alcance os critérios de fim de vida [7]. Os critérios para o fim de vida estão acerca dos números de peças produzidas, percurso de avanço $(\mathrm{mm})$, percurso efetivo de corte $(\mathrm{m})$, velocidade de corte para determinado tempo de vida, volume de material removido, acabamento superficial, entre outros [7].

De uma forma geral, a vida da ferramenta de corte está relacionada com a evolução dos desgastes da ferramenta de corte durante o processo de usinagem. No torneamento de um aço inoxidável semi-austenítico Cr12Mn5Ni4Mo3Al endurecido por precipitação, Jianxin et al. [8] observaram a ocorrência de diferentes mecanismos desgaste, tais como desgaste abrasivo, desgaste adesivo e difusão, sendo os dois últimos mais evidentes. Naves [9] destaca que no torneamento do aço inoxidável austenítico ABNT 316UF tem-se a presença de material da peça aderido às superfícies de saída e de folga, reforçando a ocorrência de desgaste por adesão.

No trabalho de Moreira [10], a principal forma de desgaste encontrado durante o serramento circular do aço inoxidável supermartensítico foi o desgaste por adesão. O melhor desempenho entre os insertos testados foi a serra com insertos revestidos por $\mathrm{Ti}(\mathrm{C}, \mathrm{N})+\mathrm{Al}_{2} \mathrm{O}_{3}+\mathrm{TiN}$ (MT-CVD) em relação aos insertos com revestimento (Ti, Al)N-TiN multicamadas (PVD) e sem revestimento.

Liew e Ding [11] investigaram o desempenho de insertos de metal duro sem e com revestimento de AlTiN durante o fresamento do aço inoxidável martensítico AISI 420. Notou-se que a alta resistência à fratura exibida pelo inserto revestido pode ter contribuído na prevenção da formação de trincas. Os resultados experimentais também mostraram que o revestimento aumentou a resistência ao desgaste abrasivo.

Liew [12] também avaliou o fresamento do aço inoxidável martensítico AISI 420 utilizando insertos 
de metal duro com revestimento TiAlN + AlCrN nano-multicamadas e TiAlN monocamada sob baixa velocidade de corte. Observou-se três fases distintas de desgaste do inserto: desgaste inicial por delaminação, atrito e abrasão seguido de trincas no substrato. A formação de trincas aumentou progressivamente, ocasionado a fratura da superfície. O inserto revestido com TiAlN $+\mathrm{AlCrN}$ exibiu maior resistência contra delaminação e desgaste abrasivo do que o inserto revestido de TiAlN. A explicação pode estar relacionada ao fato de o revestimento TiAlN + AlCrN possuir resistência à abrasão e dureza mais elevadas do que o TiAlN e à possibilidade de formação de $\mathrm{Cr}_{2} \mathrm{O}_{3}$ durante o processo, o que aumentaria ainda mais a resistência à abrasão.

Diante das informações escassas disponíveis na literatura a respeito da usinabilidade dos aços inoxidáveis supermartensíticos, o objetivo deste trabalho é avaliar a influência do material da ferramenta, velocidade de corte e pressão de aplicação do fluido de corte durante a operação de torneamento do aço inoxidável supermartensítico classe CA6NM sobre a rugosidade da superfície usinada (desvio aritmético médio Ra), vida e desgaste da ferramenta de corte.

\section{MATERIAIS E MÉTODOS}

O aço inoxidável supermartensítico (AISM) é encontrado no mercado sob as denominações SM 13CRS, 13CrSS, Super Cromo 13 ou CA6NM (segundo a norma ASTM A743). A fabricação deste aço é baseada nas normas API 5CRA e ISO 13680 [13, 14]. A dureza do material foi medida com um durômetro Heckert HPO 250 - carga de $30 \mathrm{kgf}$ aplicada durante 15 segundos, conforme a norma ASTM E92-82 [15] - e sua composição química foi avaliada por meio da espectrometria de emissão óptica. As tensões de escoamento e de ruptura foram obtidas por meio de ensaio de tração realizado em uma máquina universal SHIMADZU AG-IS com capacidade para $100 \mathrm{kN}$. A velocidade de ensaio foi correspondente a $5 \mathrm{~mm} / \mathrm{min}$ e foram utilizadas três amostras com espessura de 6,0 mm, conforme a norma ASTM E8/E8M-13a [16].

Os testes de torneamento foram realizados em um torno Romi Centur $30 \mathrm{~S}$ equipado com comando numérico computadorizado MACH 9 (potência do eixo árvore de 5,5 kW e rotação máxima de $3500 \mathrm{rpm}$ ), conforme detalhe mostrado na Figura 1. As ferramentas de corte utilizadas nos ensaios de torneamento foram insertos de metal duro Mitsubishi Carbide MC 7015 (correspondente à classe ISO M10 com dureza do substrato de 90,7 HRA e resistência à ruptura transversal de 2,0 GPa) e MC 7025 (classe ISO M10-20 com dureza do substrato de 89,4 HRA e resistência à ruptura transversal de 2,4 GPa). As duas classes possuem revestimento de TiCN $+\mathrm{Al}_{2} \mathrm{O}_{3}+$ TiN depositado por CVD. Também foram usados insertos MP 7035 (classe ISO M30-40 com dureza do substrato 89 HRA e resistência a ruptura transversal de 2,6 GPa), os quais possuem revestimento de $(\mathrm{Ti}, \mathrm{Al}) \mathrm{N}$ com alto teor de $\mathrm{Al}$ depositado por $\mathrm{PVD}$. Todos os insertos apresentam geometria ISO SNMG 120408 com quebra-cavaco MM (recomendado pelo fabricante para usinagem média) e foram montados em um porta-ferramenta ISCAR código PSSNR-JHP 2525 M12.

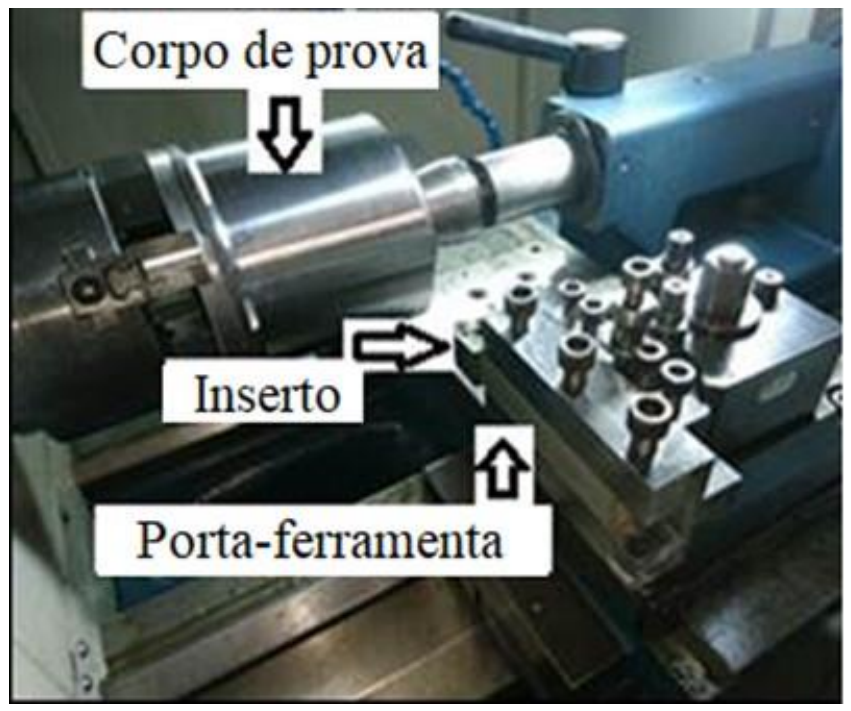

Figura 1: Montagem experimental com corpo de prova (tubo de parede grossa em aço inoxidável supermartensítico), porta-ferramenta e inserto.

A Figura 2 ilustra as condições de lubri-refrigeração sob baixa e alta pressão. Para a lubri-refrigeração sob baixa pressão (Figura 2a) utilizou-se o conjunto de refrigeração do próprio torno, composto de uma bom- 
ba com potência de $0,56 \mathrm{~kW}$ e um reservatório com capacidade para 65 litros. Para lubri-refrigeração sob alta pressão (Figura 2b) foi utilizada uma bomba centrífuga série CAM-W4C P com potência de 0,245 kW para bombear o fluido de corte do reservatório do torno para uma lavadora de alta pressão TEKNA modelo HLX140VZ com potência de $1,8 \mathrm{~kW}$, vazão de 5,7 litros /min e pressão máxima de 13,5 MPa (pressão nominal de 9,0 MPa).

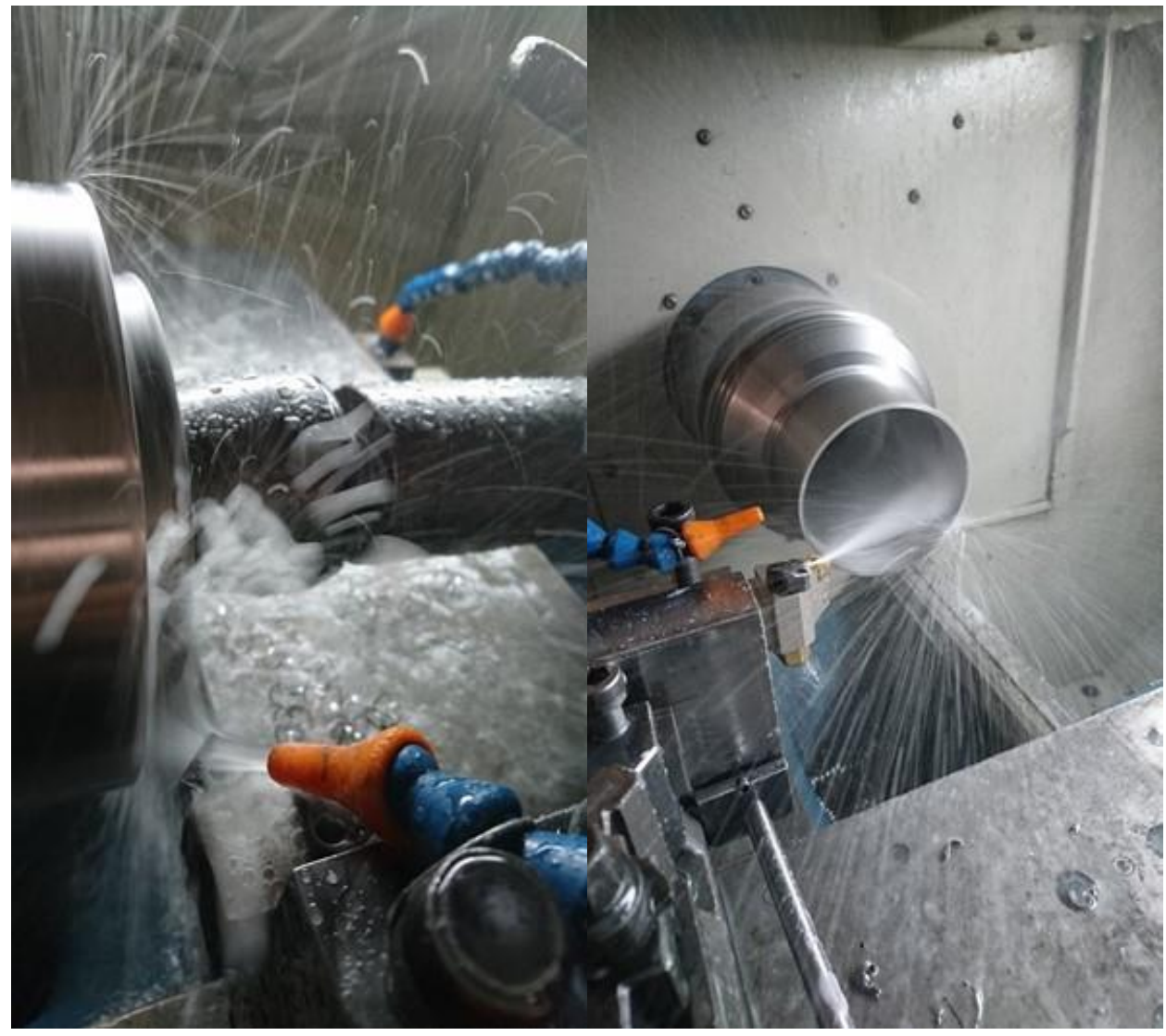

(a) Baixa pressão

(b) Alta pressão

Figura 2: Dispositivo de lubri-refrigeração: (a) baixa pressão e (b) alta pressão.

Um manômetro foi instalado para se monitorar a pressão de saída do fluido de corte nas duas situações (baixa e média pressão). No caso da lubri-refrigeração convencional, o fluido de corte foi conduzido para a mangueira flexível do próprio torno até chegar ao bocal da mangueira, como mostrado na Figura 3.0.

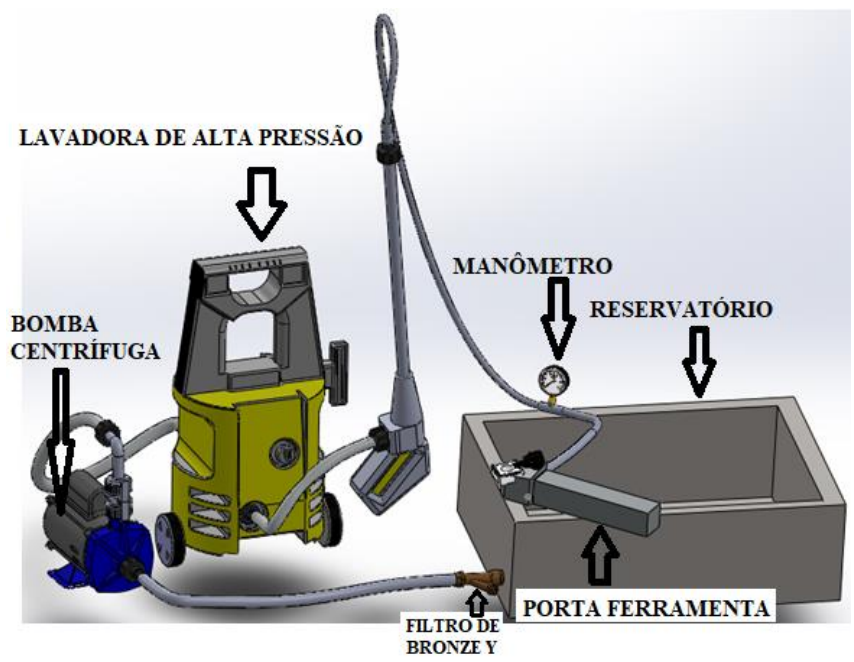

Figura 3.0: Montagem do sistema de lubri-refrigeração a média pressão. 
Foi avaliada a influência dos seguintes fatores sobre o desvio médio aritmético $(\mathrm{Ra})$ e desgaste de flanco $(\mathrm{VBc})$ : velocidade de corte $\left(v_{\mathrm{c}}\right)$, material do inserto e condição de lubri-refrigeração, como indicado na Tabela 1 (mantendo-se constantes o avanço em $0,15 \mathrm{~mm} / \mathrm{rev}$ e a profundidade de usinagem em $0,7 \mathrm{~mm}$ ), perfazendo 18 ensaios. A realização de réplicas não foi possível devido à restrição de material para confecção dos corpos de prova.

Tabela 1: Fatores e níveis empregados nos testes de torneamento.

\begin{tabular}{l|l}
\hline FATORES & NÍVEIS \\
\hline $\begin{array}{l}\text { Velocidade de corte } \\
v_{c}(\mathrm{~m} / \mathrm{min})\end{array}$ & $\begin{array}{l}200,250 \text { e } 300 \\
\text { Baixa pressão: pressão de } 0,1 \mathrm{MPa} \text {, vazão de } 4,3 \mathrm{~L} / \mathrm{min} \text { e velocidade do } \\
\text { jato de } 11,3 \mathrm{~m} / \mathrm{s} .\end{array}$ \\
Lubri-refrigeração & $\begin{array}{l}\text { Alta pressão: pressão de } 8 \mathrm{MPa}, \text { vazão de 5,01 L/min, velocidade do jato } \\
\text { de } 101 \mathrm{~m} / \mathrm{s} .\end{array}$ \\
Ferramenta & $\begin{array}{l}\mathrm{MC} 7015 \text { (ISO M10) TiCN }+\mathrm{Al}_{2} \mathrm{O}_{3}+\mathrm{TiN}(\mathrm{CVD}) . \\
\mathrm{MP} 7035 \text { (ISO M30-40) }(\mathrm{Ti}, \mathrm{Al}) \mathrm{N} \text { com alto teor de Al (PVD). }\end{array}$ \\
\hline
\end{tabular}

Após os testes de torneamento foi feita a avaliação da rugosidade das superfícies usinadas por meio do parâmetro desvio aritmético médio (Ra). As medições foram efetuadas com um rugosímetro Surtronic-25 ajustado para um comprimento de amostragem de $0,8 \mathrm{~mm}$. Para cada teste, foram realizadas três medições equidistantes em aproximadamente $120^{\circ}$ e calculada a média. Para a obtenção das imagens dos insertos e medição do desgaste utilizou-se um microscópio eletrônico de varredura Jeol JSM - 6360LV. A avaliação da vida da ferramenta foi realizada monitorando-se o desgaste de flanco VBc por um tempo de10 minutos de corte.

\section{RESULTADOS E DISCUSSÃO}

A Figura 4 apresenta micrografias do AISM sem ataque e com ataque. Em ambas as imagens nota-se a presença de $\mathrm{Ti}(\mathrm{C}, \mathrm{N})$. Além disso, a matriz martensítica pode ser visualizada na Figura 4(b). Moreira [11] comenta que o titânio é utilizado como elemento químico estabilizador e refinador de grão nos AISM. Este elemento tem influência significativa na melhoria da resistência à corrosão, propriedades mecânicas (tenacidade e resistência mecânica) e na formação de carbonitretos, tais como Ti(C,N). Por meio da espectroscopia de dispersão de energia (EDS - Energy Dispersion Spectroscopy) foi realizada a análise no ponto 1. A presença de titânio neste ponto, indicada na Figura 5, associada à imagem apresentada na Figura 4(b), reforça a possibilidade de formação do carbonitreto de titânio. 


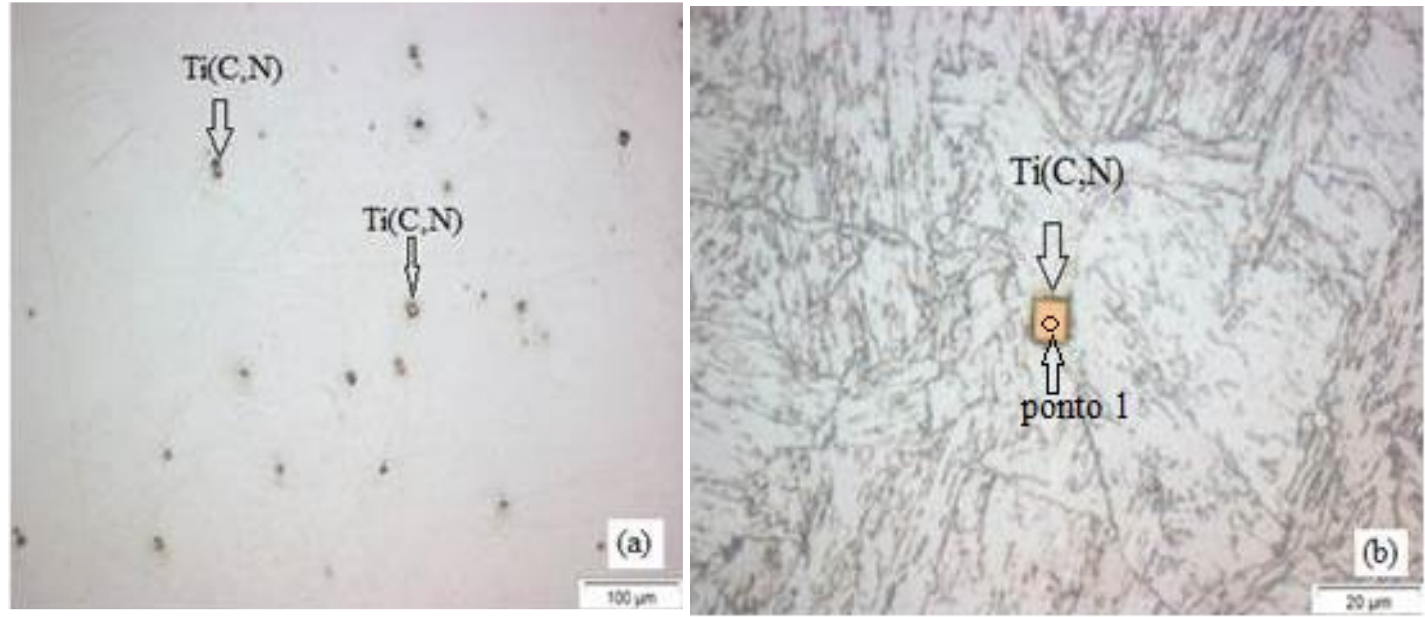

Figura 4: Micrografia do aço inoxidável supermartensítico: (a) sem ataque e (b) precipitado de carbonitreto de titânio sobre a matriz martensítica.

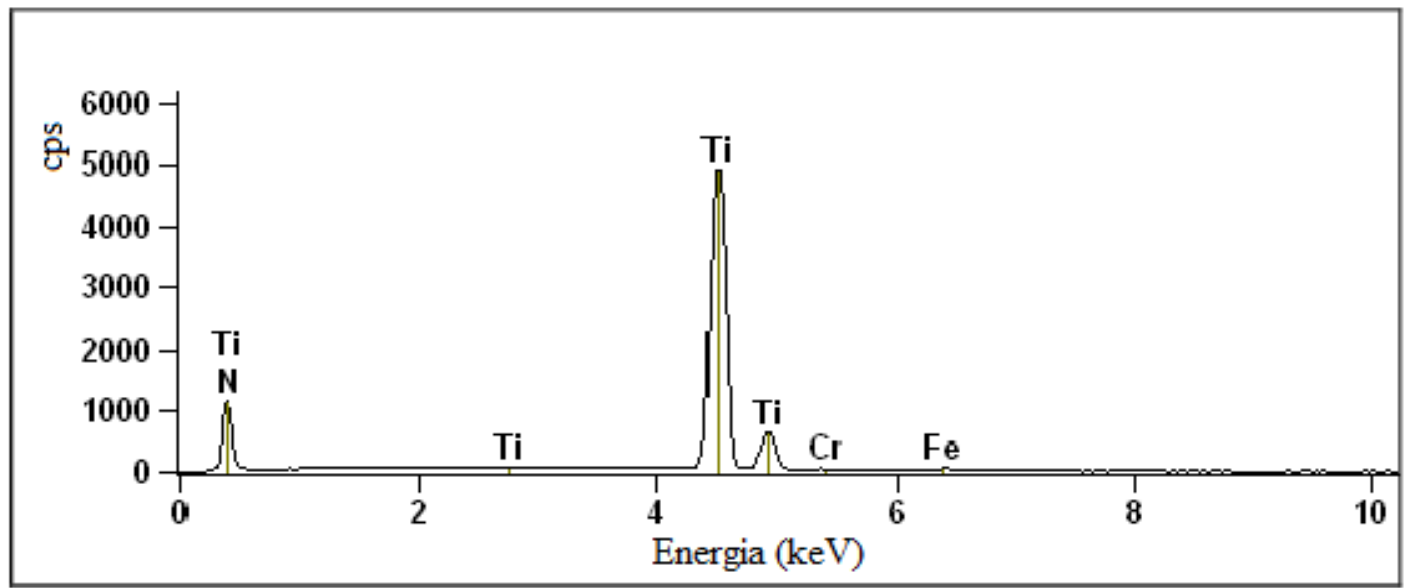

Figura 5: Análise por EDS do ponto 1.

Machado et al. [4] afirmam que a presença de Ti nos aços inoxidáveis torna a sua usinagem mais difícil devido à possibilidade de formação de $\mathrm{Ti}(\mathrm{C}, \mathrm{N})$. O titânio inibe a precipitação de carbonitretos de cromo, molibdênio e vanádio, cuja formação reduz a resistência à corrosão e causa endurecimento secundário após revenimento. Por outro lado, o excesso de titânio provoca a precipitação de compostos intermetálicos tais como TiNi, que aumentam o endurecimento secundário [11]. O resultado da análise química por espectrometria de emissão óptica é apresentado na Tabela 2.

Tabela 2: Análise da composição química do AISM.

\begin{tabular}{l|c}
\hline ELEMENTO & CONCENTRAÇÃO (\% em massa) \\
\hline Carbono & 0,014 \\
Cromo & 11,75 \\
Molibdênio & 1,93 \\
Níquel & 5,55 \\
Titânio & 0,14 \\
\hline
\end{tabular}

Klocke [17] destaca que os aços com teor de carbono (C) menor que 0,25\% têm uma elevada tendência à adesão e formação de aresta postiça de corte. Materiais com este teor de carbono podem ser caracterizados pela estrutura ferrítica. Aços com esta característica apresentam tendência à formação de rebarbas. Elementos como cromo $(\mathrm{Cr})$ e molibdênio (Mo), associados aos carbonetos presentes no aço prejudicam a usinabilidade do material, pois carbonetos de cromo e de molibdênio são partículas duras e abrasivas. Ligas com o alto teor de molibdênio proporcionam um aumento da dureza e maiores forças de usinagem [18]. O elemen- 
to níquel (Ni) também têm tendência a formar aresta postiça de corte, o que pode promover desgaste de entalhe. $\mathrm{O}$ alto teor de níquel dos aços inoxidáveis austeníticos dificulta sua usinagem, pois resulta em maior taxa de encruamento e baixa condutividade térmica [18]. Segundo Klocke [17], o titânio presente na liga não é favorável à usinagem porque aumentam os esforços mecânicos para a formação do cavaco. A presença de Ti dificulta a usinagem, pois este elemento forma o elemento carbonitreto de titânio $\operatorname{Ti}(\mathrm{C}, \mathrm{N})$, que possui elevada abrasividade.

O valor de dureza média do AISM é de $290 \pm 6,06 \mathrm{HV}$ e as tensões limite de escoamento e de resistência, respectivamente, 738,7 e 794,7 MPa. Os valores de tensão limite de escoamento e de resistência do aço inoxidável supermartensítico são mais elevados em comparação aos aços inoxidáveis martensíticos, duplex, ferríticos e austeníticos. $\mathrm{O}$ valor do coeficiente $\mathrm{k}$, que quantifica o nível de resistência que o material pode suportar, é 1346,14 $\pm 37,63 \mathrm{MPa}$ e o valor do expoente $\mathrm{n}$, que representa a capacidade com que o material distribui a deformação, é $0,177 \pm 0,019$. Desta forma, o valor da tensão verdadeira $(\sigma)$ pode ser expresso em função da deformação $(\varepsilon)$ por meio da Equação (1). Os valores encontrados para k e n situam-se na faixa tipicamente encontrada na literatura [14,19].

$$
\sigma=1346,14 \cdot \varepsilon^{0,177}
$$

Os resultados da análise de variância para os valores de rugosidade (desvio médio aritmético Ra) e desgaste de flanco (VBc) obtidos após o torneamento do AISM são apresentados na Tabela 3. Se o p-valor for maior que o nível de significância $(\alpha=0,05)$, rejeita-se a hipótese nula de que os fatores apresentem influência estatística para um nível de confiança de $95 \%$. Identifica-se na Tabela 3 que nenhum fator ou interação apresentou influência significativa sobre o desvio médio aritmético (Ra). Para o desgaste de flanco (VBc) medido após 10 minutos de corte os dados apresentados na Tabela 3 apontam p-valor $<0,05$ para os fatores velocidade de corte $\left(v_{c}\right)$, inserto, lubri-refrigeração e interação entre inserto e lubri-refrigeração, o que significa que tais fatores apresentam influência estatisticamente significativa sobre VBc. Porém, a interação entre inserto e lubri-refrigeração requer uma atenção devido o p-valor estar próximo de 0,05 .

Tabela 3: Análise de variância para desvio médio aritmético (Ra) e para o desgaste de flanco (VBc).

\begin{tabular}{c|c|c|c}
\hline FONTE & $\begin{array}{c}\text { GRAU DE } \\
\text { LIBERDADE }\end{array}$ & $\begin{array}{c}\left.\mathbf{( R}_{\mathbf{A}}\right) \\
\text { P-VALOR }\end{array}$ & $\begin{array}{c}\left.\mathbf{( V B}_{\mathrm{c}}\right) \\
\text { P-VALOR }\end{array}$ \\
\hline$v_{\mathrm{c}}$ & 2 & 0,846 & 0,001 \\
Inserto & 2 & 0,100 & 0,000 \\
Lubri-refrigeração & 1 & 0,408 & 0,003 \\
$v_{\mathrm{c}}$ X inserto & 4 & 0,586 & 0,140 \\
$v_{\mathrm{c}}$ x Lubri-refrigeração & 2 & 0,152 & 0,284 \\
Inserto x Lubri-refrigeração & 2 & 0,757 & 0,042 \\
Erro & 4 & & \\
Total & 17 & & \\
\hline
\end{tabular}

Embora nenhum fator ou interação tenha apresentado influência significativa sobre Ra, a Figura 6 mostra que a elevação da velocidade de corte promoveu uma leve redução na dispersão dos valores de rugosidade, o que é bastante desejável para o controle do processo. A Figura 7 mostra que a ferramenta MC 7015 promoveu valores médios de rugosidades mais baixos $(\mathrm{Ra}=0,93 \mu \mathrm{m})$ embora estes não sejam estatisticamente significativos, independentemente da pressão do fluido de corte. Observa-se que as rugosidades (Ra) para as ferramentas MC7015 e MC7025 na condição de baixa pressão, podem ser consideradas semelhantes, uma vez que houve alta variabilidade da rugosidade quando foi utilizado o inserto MC7025 sob condição de baixa pressão de lubri-refrigeração. Foi utilizado o teste estatístico de Tukey para comparar as médias entre os pares. Se um intervalo não contiver o zero, as médias correspondentes serão significativamente diferentes. Portanto, observou-se que tanto para a lubri-refrigeração (Figura 8), inserto (Figura 9) e as interações (Figura 10) as médias entre os pares não são diferentes. 


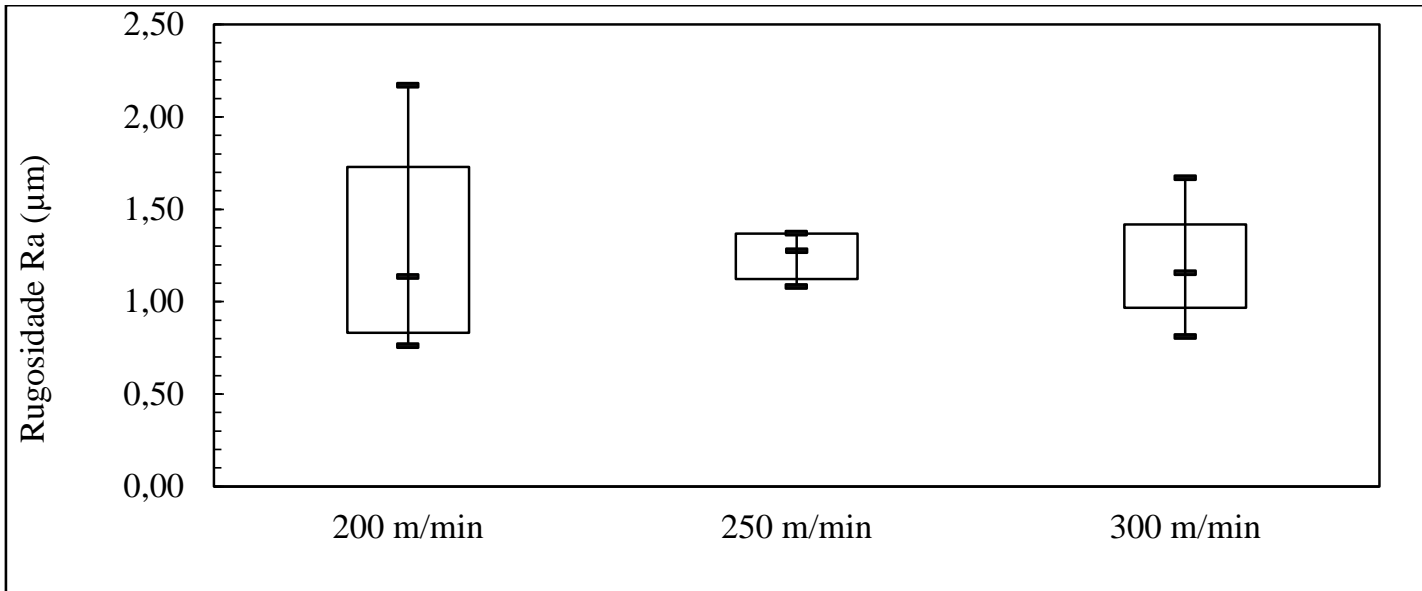

Figura 6: Box plot da influência da velocidade de corte sobre a rugosidade Ra.

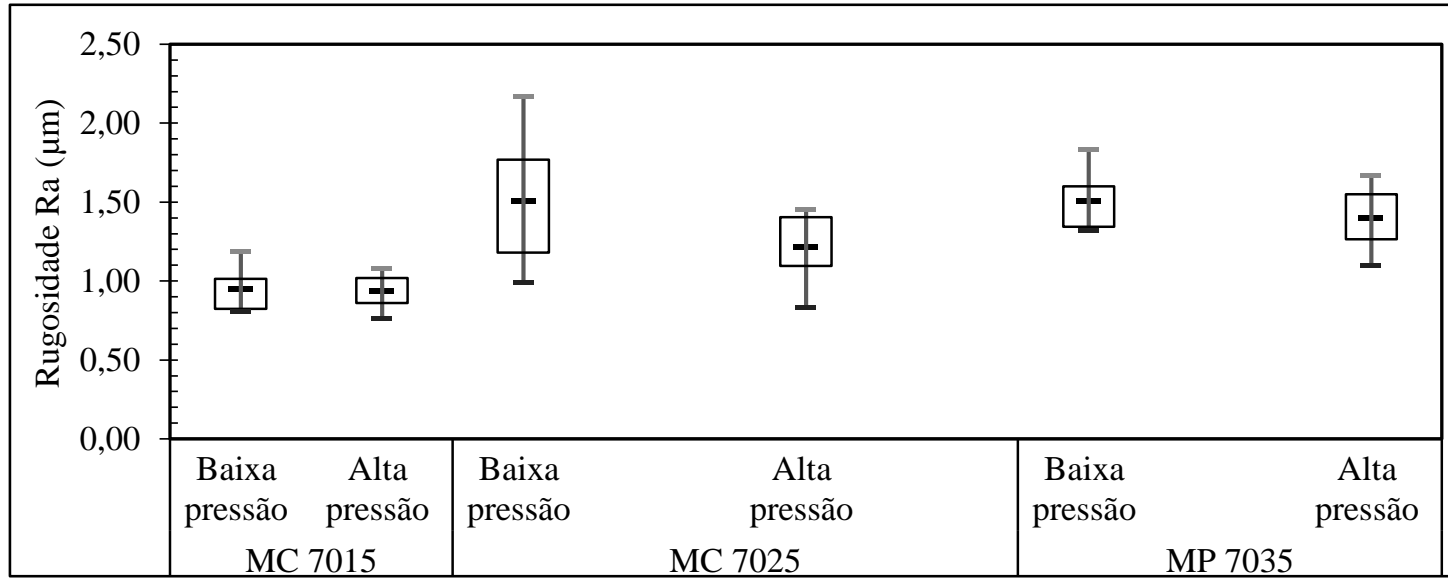

Figura 7: Box plot da influência da lubri-refrigeração e inserto sobre a rugosidade Ra.

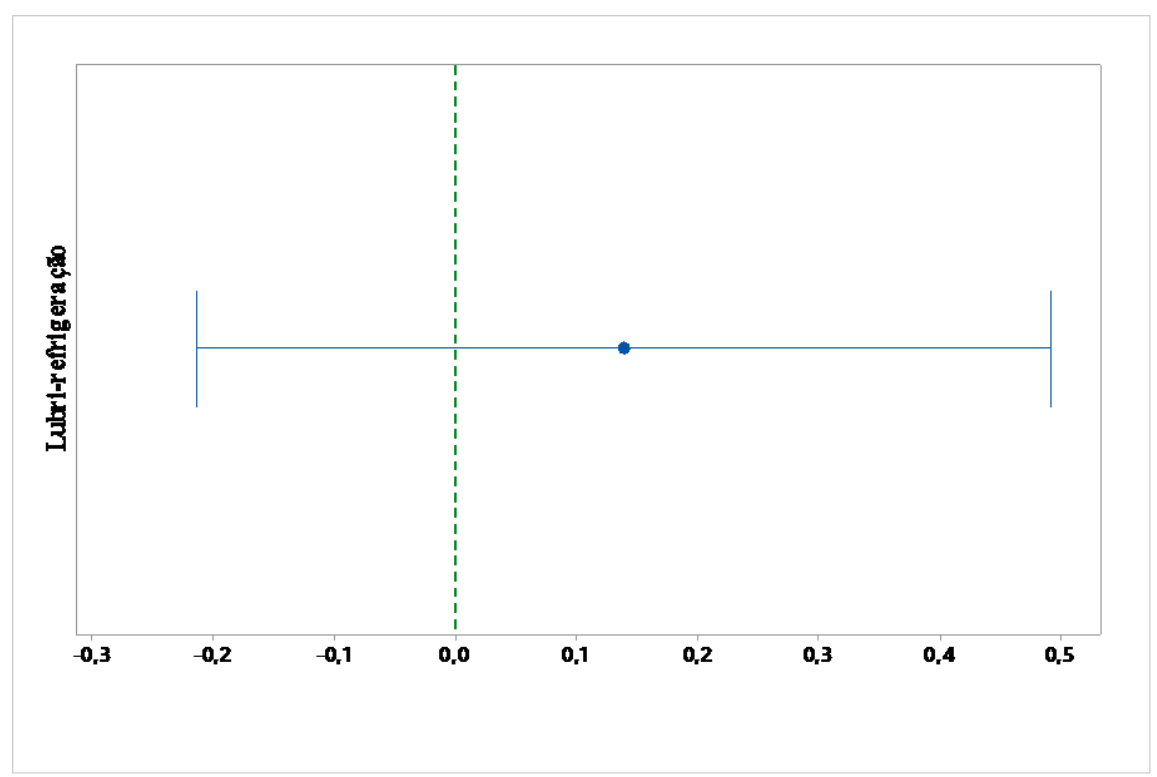

Figura 8.0: Teste Tukey para o fator lubri-refrigeração. 


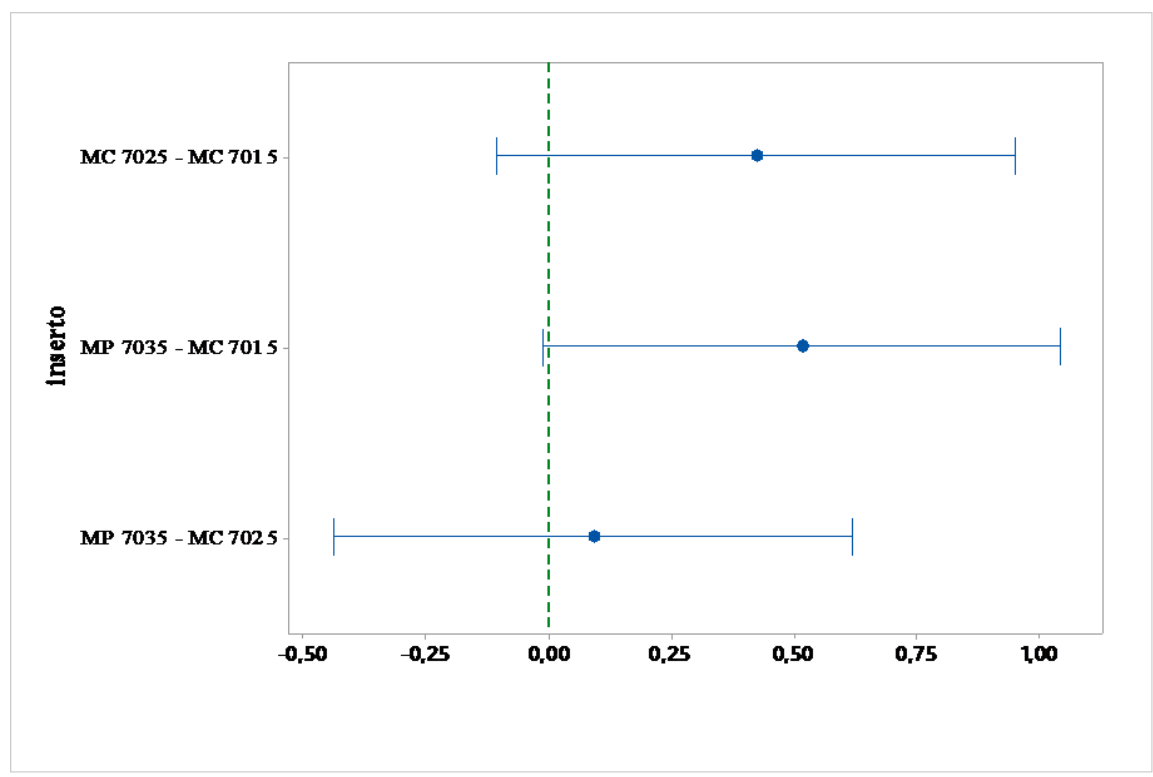

Figura 9: Teste Tukey para o fator inserto.

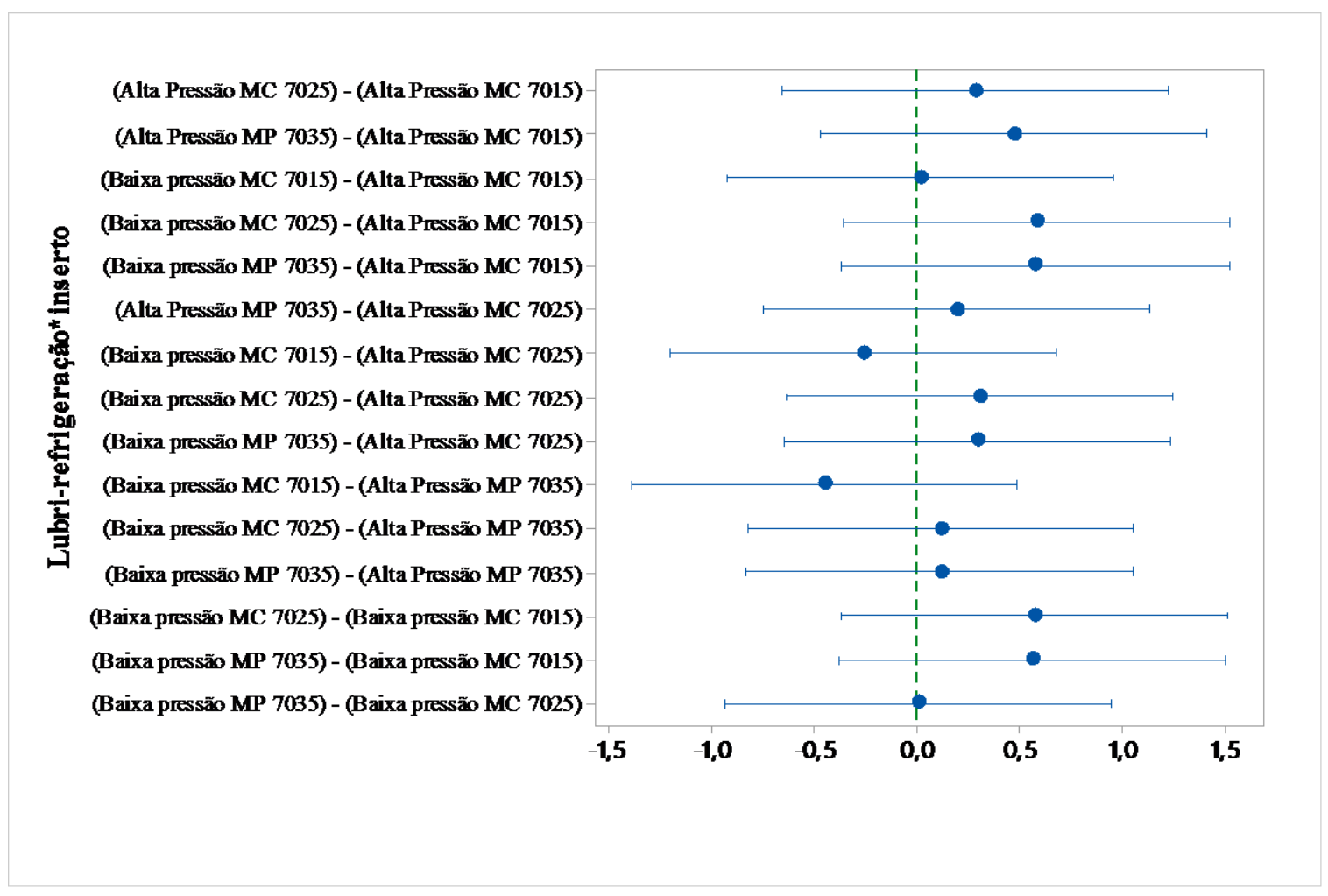

Figura 10: Teste Tukey para as interações.

A Figura 11 apresenta a influência da velocidade de corte sobre o desgaste de flanco. Nota-se que a velocidade de corte de $200 \mathrm{~m} / \mathrm{min}$ apresentou o menor valor de $\mathrm{VBc}$, seguida das velocidades de corte de 250 e $300 \mathrm{~m} / \mathrm{min}$. O aumento da velocidade de corte está ligado à elevação da temperatura na interface inserto/cavaco. Esta elevação de temperatura promove o aumento da oxidação e deformação plástica dos revestimentos, levando-os ao colapso e a taxas mais elevadas de desgaste [20]. A presença de Ti foi um dos fatores que influenciou a taxa de desgaste, pois este elemento forma carbonitreto de titânio $\mathrm{Ti}(\mathrm{C}, \mathrm{N})$, que possui elevada abrasividade. 


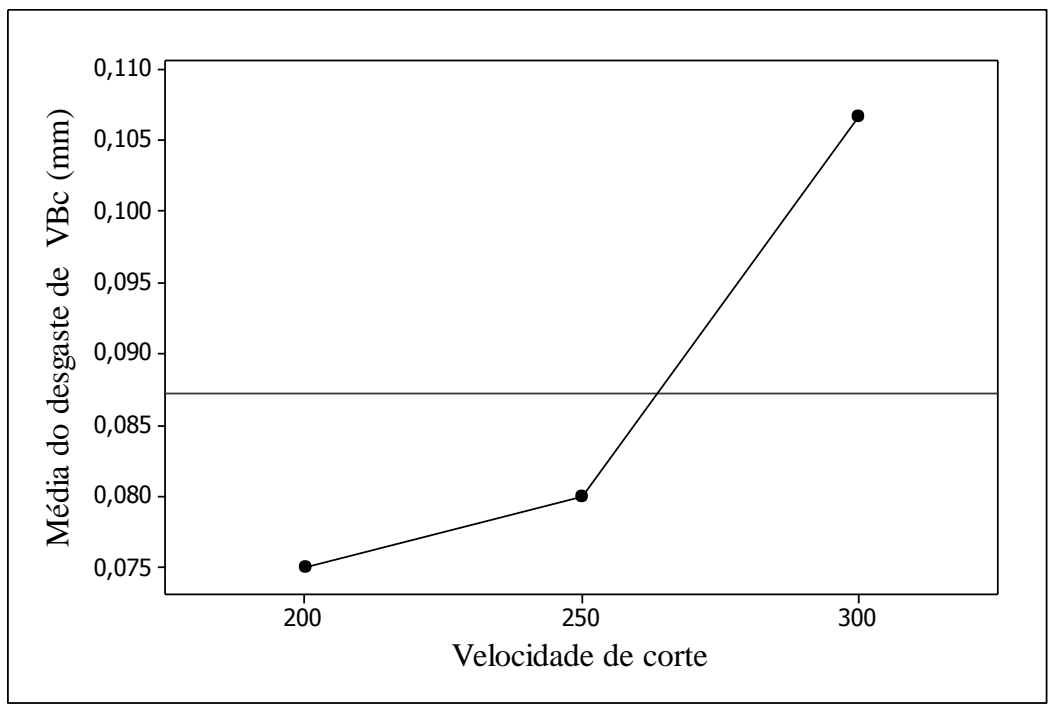

Figura 11: Influência da velocidade de corte sobre o desgaste de flanco (VBc).

A Figura 12 apresenta a influência do material do inserto sobre o desgaste de flanco. Observa-se que o inserto MC 7015 apresentou o menor valor médio do desgaste de flanco, seguido de perto pelo inserto MC 7025 e pelo MP 7035. Uma possível explicação do comportamento quanto ao desgaste de flanco (VBc) dos insertos está relacionada à perda dos revestimentos em função dos mecanismos de desgaste predominantes e das tensões na região de corte [21]. O inserto MP 7035 possui revestimento monocamada de (Ti, Al)N com alto teor de $\mathrm{Al}$, o que pode ter contribuído para o desgaste acelerado, enquanto que os insertos MC 7015 e 7025 têm o mesmo revestimento $\mathrm{TiC}, \mathrm{N}+\mathrm{Al}_{2} \mathrm{O}_{3}+\mathrm{TiN}$, porém, são multicamadas que retardam a perda de material. A camada externa de TiN apresenta menor coeficiente de atrito e consegue reduzir o contato da peça com cavaco, retardando o desgaste. Uma possível falha prematura do revestimento $(\mathrm{Ti}, \mathrm{Al}) \mathrm{N}$ levou a maior exposição do substrato e, consequentemente, a um desgaste mais intenso [22]. Além disso, este revestimento tem a capacidade de transformar-se em um novo composto $\left(\mathrm{Al}_{2} \mathrm{O}_{3}\right)$, que tem afinidade química com a camada passivadora de $\mathrm{Cr}_{2} \mathrm{O}_{3}$, promovendo adesão e contribuindo para o desgaste do inserto [17].

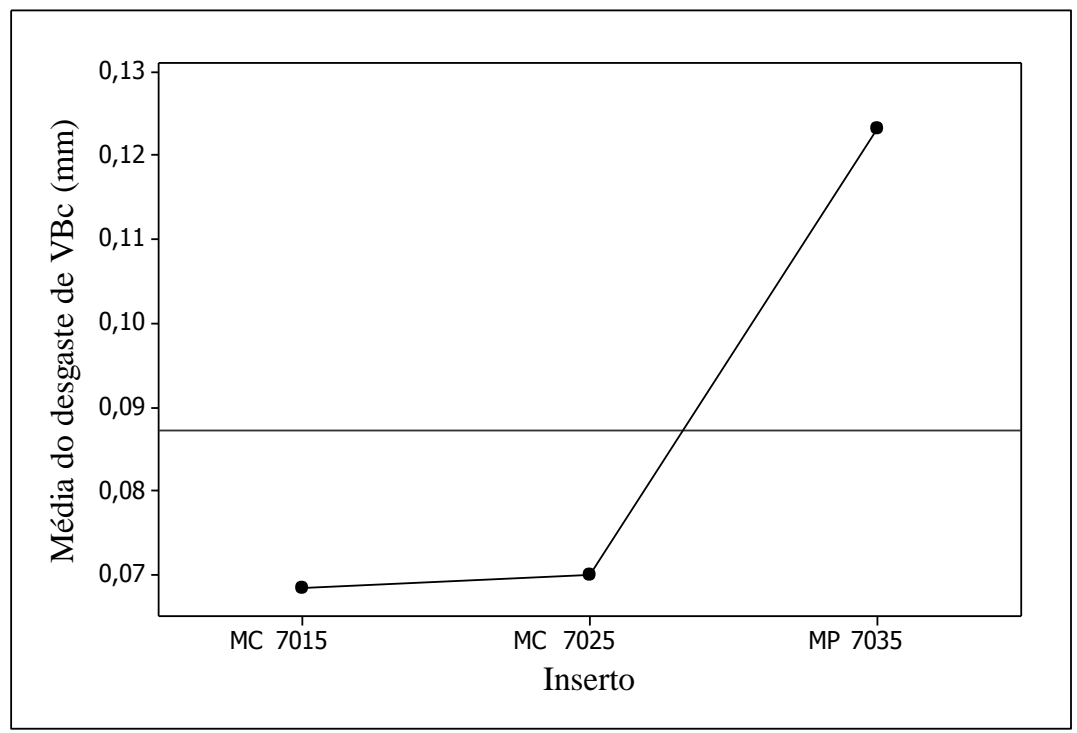

Figura 12: Influência do inserto sobre o desgaste de flanco (VBc).

A Figura 13 apresenta a influência da lubri-refrigeração sobre o desgaste de flanco. Nota-se que a lubri-refrigeração sob alta pressão é a condição que proporciona os menores valores de VBc. Uma possível explicação para a lubri-refrigeração sob alta pressão resultar em menor desgaste de flanco seria a formação de uma cunha hidráulica entre o cavaco e a superfície de saída do inserto pelo jato sob alta pressão [23], o que minimizaria a área de contato entre cavaco e inserto. Além disso, o fluido sob alta pressão apresenta 
maior efeito refrigerante. A Figura 14 ilustra a influência da interação entre inserto e lubri-refrigeração sobre o desgaste de flanco. Nota-se que a lubri-refrigeração sob alta pressão associada ao inserto MC 7015 apresentou menor valor de desgaste VBc, seguida dos insertos MC 7025 e MP 7035.

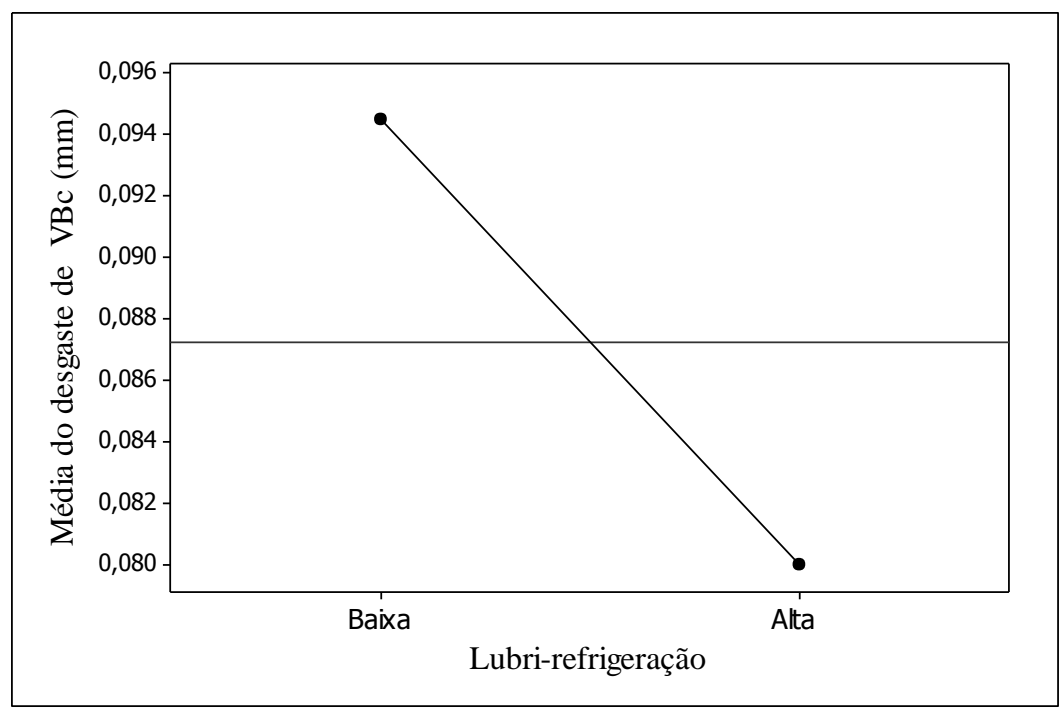

Figura 13: Influência da lubri-refrigeração sobre o desgaste de flanco (VBc).

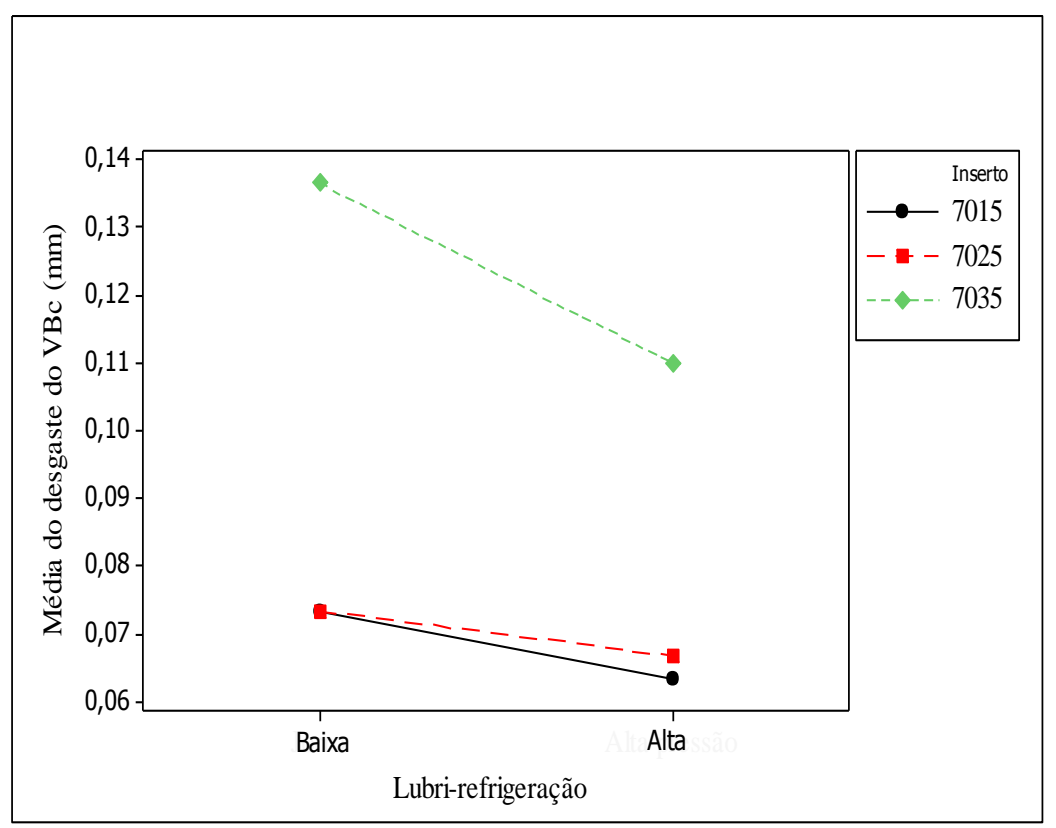

Figura 14: Interação entre o inserto e a lubri-refrigeração sobre o desgaste VBc.

As Figuras 15 e 16 apresentam a evolução do desgaste VBc do inserto MC 7015 em função da velocidade de corte $(f=0,15 \mathrm{~mm} / \mathrm{rev}$ e ap $=0,7 \mathrm{~mm})$ ao longo de 10 minutos nas condições de lubri-refrigeração sob baixa e alta pressão. Como o inserto MC 7015 foi o que apresentou melhores resultados em relação a Ra e VBc, optou-se por apresentar somente a vida deste inserto. Observa-se na Figura 15 que o desgaste do inserto foi maior ao final de um tempo de corte de 10 minutos quando submetido à velocidade de corte de 300 $\mathrm{m} / \mathrm{min}$, seguido por 250 e $200 \mathrm{~m} / \mathrm{min}$. A Figura 16 apresenta comportamento semelhante à Figura 15 , porém, quando o torneamento foi realizado sob baixa pressão, o valor do desgaste do inserto MC 7015 foi um pouco maior em relação à condição de lubri-refrigeração sob alta pressão. Observa-se ainda que com o aumento da velocidade de corte, a taxa de desgaste é crescente, porém a penetração do jato com alta energia cinética na interface cavaco/inserto reduz o desgaste por minimizar o contato na zona de aderência, favorecendo a lubrificação e redução da temperatura e do atrito na interface cavaco-ferramenta [11;24]. 


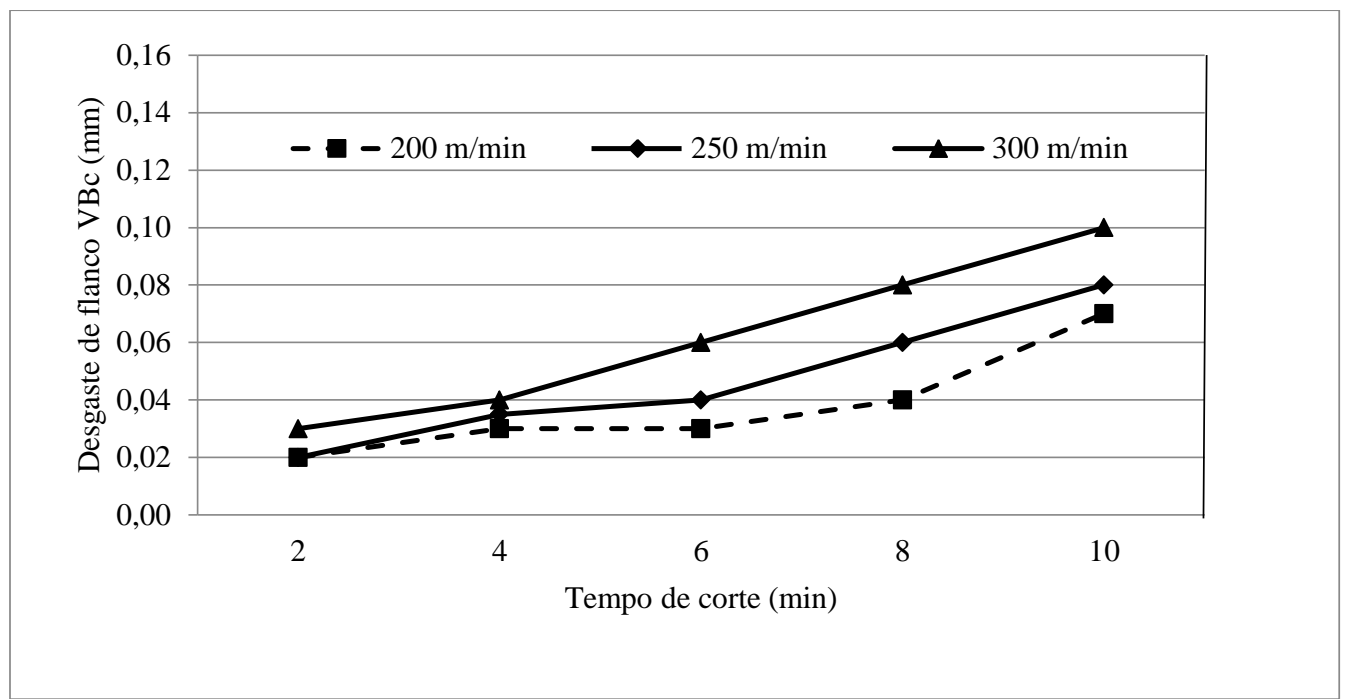

Figura 15: Vida do inserto MC 7015 sob distintas $v_{c}$ e lubri-refrigeração sob baixa pressão $(t=10$ min).

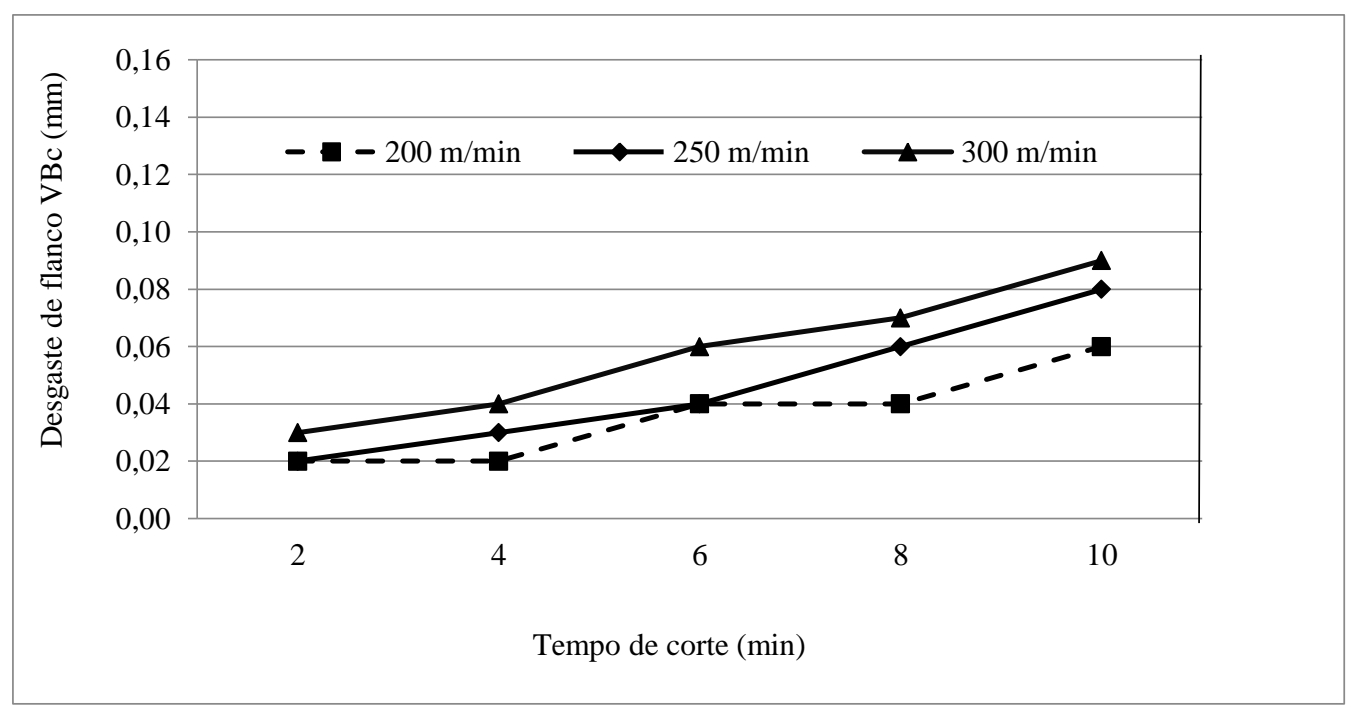

Figura 16: Vida do inserto MC 7015 sob distintas $v_{c}$ e lubri-refrigeração sob alta pressão $(t=10$ min).

A Figura 17 apresenta imagens de desgaste do inserto MC 7015 sob velocidades de corte e condições de lubri-refrigeração distintas. Ao avaliar o desgaste sob $v_{\mathrm{c}}=200 \mathrm{~m} / \mathrm{min}$ na condição da lubri-refrigeração sob baixa pressão (Figura 17a), nota-se a ocorrência do desplacamento de parte do revestimento e a exposição do substrato. A Figura 17(b) sugere desgaste por abrasão leve sob $v_{c}=250 \mathrm{~m} / \mathrm{min}$ e a Figura 17(c) mostra que sob velocidade de corte de $300 \mathrm{~m} / \mathrm{min}$ ocorre o desgaste por abrasão leve na superfície de folga e saída do inserto e microlascamento da aresta de corte. As Figuras 17(d), 17(e) e 17(f) indicam o desgaste por abrasão e desplacamento do revestimento em todas as faixas de velocidades de corte testadas quando utilizou-se lubri-refrigeração sob alta pressão. Comparando as Figuras 17(a) e 17(d), nota-se que o comportamento do desgaste foi similar. O mesmo é observado ao se comparar as Figuras 17(b) e 17(e) e as Figuras 17(c) e $17(\mathrm{f})$, porém, o desgaste dos insertos é de menor intensidade quando o fluido de corte é aplicado sob alta pressão. Embora as imagens apresentadas na Figura 17 não permitam uma comparação direta dos níveis de desgaste alcançados devido ao fato de terem sido registradas com os insertos inclinados e sob diferentes ampliações, a medição do desgaste das ferramentas empregando um microscópio ferramenteiro e em conformidade com a norma ISO 3685 (1993) [7] permite afirmar que o uso fluido de corte sob alta pressão reduziu o desgaste das ferramentas de corte. 


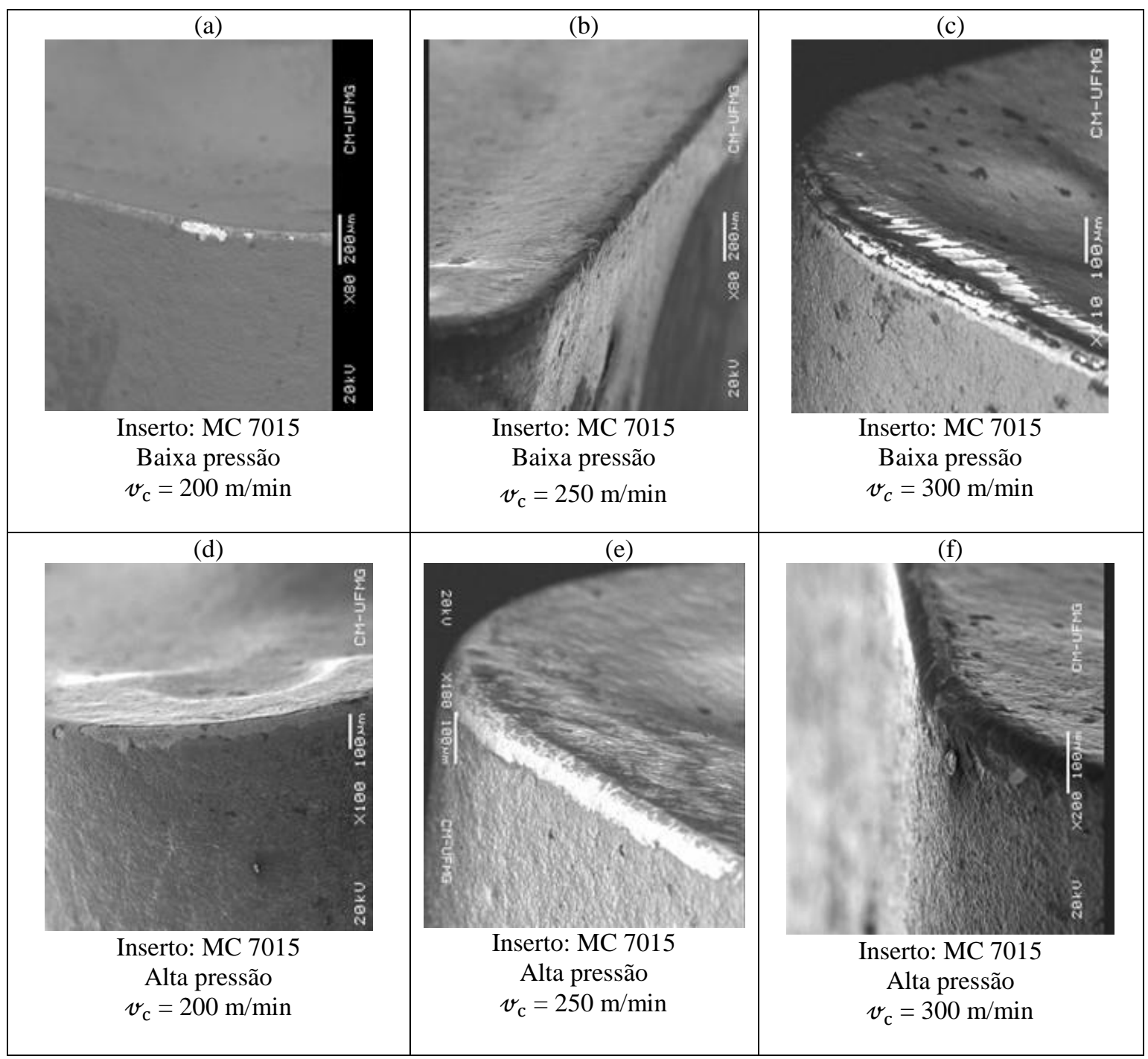

Figura 17: Desgaste dos insertos MC 7015 quando submetidos a lubri-refrigeração sob baixa pressão e velocidades de corte de (a) 200, (b) 250 e (c) $300 \mathrm{~m} / \mathrm{min}$ e sob alta pressão e velocidades de corte de (d) 200, (e) 250 e (f) $300 \mathrm{~m} / \mathrm{min}$.

Em síntese, o teor elevado de níquel promoveu maior taxa de encruamento e contribuiu para a baixa condutividade térmica o que leva a baixa difusividade térmica do AISM. Quando materiais com baixa difusividade são submetidos ao corte, a concentração de calor na região de corte pode não apresentar o benefício desejado: a temperatura elevada promove ainda mais o amolecimento e deformação do material e consequentemente, maior adesão e desgaste da ferramenta. Além disso, valores dos coeficientes n e k apresentados demostram que o AISM apresenta taxa de encruamento (n) e nível de resistência (k) mais elevados em comparação aos aços inoxidáveis martensíticos, duplex, ferríticos e austeníticos.

De acordo com Mitsubishi [25], o inserto de metal duro com maior dureza (MC 7015) apresenta condutividade térmica mais baixa (menor dissipação do calor gerado, devido a maior concentração dos elementos, TiC ou TaC e WC (materiais cerâmicos) em comparação ao inserto de metal duro com maior tenacidade (MC 7025 e MP 7035) devido a maior concentração de Cobalto.

Embora não exista influência estatística dos parâmetros de corte estudados sobre a rugosidade Ra, foi observado que o inserto MC 7015 apresentou menor taxa de desgaste e propiciou menores valores médios e menor dispersão nos resultados. Portanto, existe uma possibilidade das variáveis respostas, rugosidade e desgaste de flanco, se influenciarem mutuamente. 


\section{CONCLUSÕES}

Após a realização de testes de caracterização e de torneamento do aço inoxidável supermartensítico, concluise que:

- Os resultados da análise química por espectrometria de emissão permitiram quantificar as concentrações de cromo (11,75\%), níquel $(5,55 \%)$, molibdênio $(1,93 \%)$ e titânio $(0,14 \%)$ e classificar o material em estudo como aço inoxidável supermartensítico de média liga. A presença do elemento químico Ti possibilitou a formação de Ti(C,N), o qual aumenta a abrasividade do material e os esforços mecânicos para a formação do cavaco.

- O material apresenta tensão limite de escoamento de 738,7 MPa, tensão limite de resistência de 794,7 MPa, coeficiente de resistência $\mathrm{k}=1346,1 \mathrm{MPa}$ e grau de encruamento $\mathrm{n}=0,177$. O valor médio de dureza do aço inoxidável supermartensítico é $290 \mathrm{HV}$.

- A rugosidade da superfície usinada não foi afetada estatisticamente pelos fatores analisados, no entanto, o aumento da velocidade de corte reduziu a dispersão dos dados e o inserto MC 7015 proporcionou menores valores médios de rugosidade, independentemente da pressão de aplicação do fluido de corte.

- O desgaste de flanco aumentou com a velocidade de corte e diminuiu com o aumento da pressão do fluido de corte. Além disso, o inserto MC 7015 foi o que apresentou menor desgaste, seguido de perto do inserto MC 7025. Ambos insertos possuem revestimento de TiCN $+\mathrm{Al}_{2} \mathrm{O}_{3}+$ TiN depositado por CVD. O inserto MC 7035, que possui revestimento de (Ti, $\mathrm{Al}) \mathrm{N}$ com alto teor de $\mathrm{Al}$ depositado por PVD, apresentou pior desempenho.

- Por meio de imagens da cunha dos insertos, constatou-se que o aumento da velocidade de corte promoveu o aumento do desgaste para todos insertos. Independentemente do tipo da lubri-refrigeração, sob velocidade de corte $300 \mathrm{~m} / \mathrm{min}$ o desgaste de flanco se fez presente de forma mais acentuada, no entanto, com lubri-refrigeração sob alta pressão o desgaste de flanco foi atenuado.

- Todos os insertos apresentaram desgaste gradual, com ocorrência do desplacamento de parte do revestimento e exposição do substrato próximo ao raio de ponta. Evidenciou-se a presença de desgaste por abrasão.

\section{AGRADECIMENTOS}

Os autores agradecem ao Programa de Pós-Graduação em Engenharia de Produção da Universidade Federal de Minas Gerais por viabilizar a realização deste trabalho, à Kampmann do Brasil Ltda., pela doação das amostras de aço inoxidável supermartensítico e às agências CNPq, CAPES e FAPEMIG pelo apoio a este projeto.

\section{BIBLIOGRAFIA}

[1] PETROBRAS. http://www.petrobras.com.br/ acessado em março de 2019.

[2] ABINOX, Associação Brasileira do Aço Inoxidável. http://www.abinox.org.br/ acessado em janeiro 2019.

[3] MORELO, F. "Análise da influência do mandrilamento na integridade superficial do aço inoxidável super duplex”. Dissertação de M.Sc., Universidade Tecnológica Federal do Paraná, Curitiba, 2014.

[4] MACHAdO, A. R. COELHO, R. T. ABRÃO, A. M., et al., Teoria da Usinagem dos Materiais, $3{ }^{a}$ Ed. Edgard Blücher, São Paulo, 384 p. 2015.

[5] KALPAKJIAN, S. SCHMID, S. R. Manufacturing Engineering and Technology, 4th ed, New Jersey, Prentice-Hall, 2001.

[6] OLIVEIRA, D. A. DE. Influência da modificação da geometria da ferramenta de corte sobre o torneamento do aço inoxidável supermartensítico, Dissertação de M.Sc., Universidade Federal de Minas Gerais, Belo-horizonte, 2017.

[7] ISO 3685, International Organization For Standardization: Tool-life testing with single-point turning tools. 48 p. 1993.

[8] JIANXIN, D., JIANTOU, Z. HUI, Z., et al., "Wear mechanisms of cemented carbide tools in dry cutting of precipitation hardening semi-austenitic stainless steel”, Wear, v. 270, pp.520-527, 2011. 
[9] NAVES, V. T. G. "Usinagem do aço inoxidável austenítico ABNT 316 UF com aplicação de fluido de corte a alta pressão", Tese de D.Sc., Universidade Federal de Uberlândia, Uberlândia, 2013.

[10] MOREIRA, M. C. "Usinabilidade do aço inoxidável supermartensítica durante o serramento circular utilizando serras com insertos intercambiáveis de metal duro revestidos e sem revestimento", Tese de D.Sc., Universidade Federal de Minas Gerais, Belo Horizonte, 2016.

[11] LIEW, W.Y.H., DING, X. "Wear progression of carbide tool in low-speed end milling of stainless steel”, WEAR, pp. 155-166, nov. 2008.

[12] LIEW, W.Y.H., "Low-speed milling of stainless steel with TiAlN single-layer and TiAlN/AlCrN nanomultilayer coated carbide tools under different lubrication conditions", WEAR, pp. 617-631, v. 269, 2010.

[13] ISO 13680, INTERNATIONAL ORGANIZATION FOR STANDARDIZATION. "Petroleum and natural gas industries - Corrosion-resistant alloy seamless tubes for use as casing, tubing and coupling stock Technical delivery conditions", First Edition, July 1, 2000.

[14] SUMITOMO METAL INDUSTRY, SM12CRS-110, Japão, Dados Técnicos, 2011, 6p.

[15] ASTM E92-82, AMERICAN SOCIETY FOR TESTING AND MATERIALS: Standard Test Method for Vickers Hardness of Metallic, 9 p, 2003.

[16] ASTM E8 / E8M - 13A, AMERICAN SOCIETY FOR TESTING AND MATERIALS: Standard Test Methods for Tension Testing of Metallic Materials. Estados, 28 p, 2013.

[17] KLOCKE, F. Manufacturing processes 1: Cutting. Berlin, Springer, 2011. 517 p.

[18] SHAW, M. C., Metal cutting principles, 2 ed., Nova York (Estados Unidos da América), Oxford University Press, 651 p, 2005.

[19] VALLOUREC TUBOS DO BRASIL S.A., 13\%Cr \& Super 13\%Cr steel grades for sweet CO2 corrosion service V\&M Tubes, Catálogo, 8 p, 2005.

[20] AGUIAR, H.C. G. "Contribuição ao estudo do torneamento do aço inoxidável superduplex empregando ferramentas de metal duro com revestimentos”, Dissertação de M.Sc., Curso de Engenharia Mecânica, Área de Materiais e Processo de Fabricação, Faculdade de Engenharia Mecânica da Universidade Estadual de Campinas, Campinas, 2012.

[21] EZUGWU, E, O., LAJIRE, K, A., JAWAID, A. "Wear performance of multilayer- coated carbide tools”, Machining Science And Technology Coventry University, pp. 115-129, 10 jan. 2001.

[22] RODRIGUES, H. L. "Relação desgaste-acabamento superficial em ferramentas de metal duro com revestimento tripulo no torneamento de aços”, Tese de D.Sc., Curso de Engenharia Mecânica, Projetos e Materiais, Universidade Estadual Paulista, Guaratinguetá, 2005.

[23] KROLCZYK, G. NIESLONY, P. LEGUTKO, S. "Microhardness and Surface Integrity in Turning Process of Duplex Stainless Steel (DSS) for Different Cutting Conditions", Journal of Materials Engineering and Performance, v. 23, pp. 859-859, 2013.

[24] NAVES, V.T.G., SILVA, M.B., SILVA. F. J. "Evaluation of the effect of application of cutting fluid at high pressure on tool wear during turning operation of AISI 316 austenitic stainless steel”, Wear, pp. 12011208, 29 Mar. 2013.

[25] MITSUBISHI. Catálogo. MITSUBISHI MATERIALS. 2016. http://www.mitsubishicarbide.com/. Acessado em janeiro 2019.

\section{ORCID}

Deibe Valgas dos Santos Alexandre Mendes Abrão Anderson Júnior dos Santos https://orcid.org/0000-0001-7024-2345

https://orcid.org/0000-0003-2015-4077

https://orcid.org/0000-0002-5285-3289 